\title{
Heterogeneous topographic profiles of kinetic and cell cycle regulator microsatellites in atypical (dysplastic) melanocytic nevi
}

\author{
Ehab A Husain ${ }^{1}$, Charles Mein ${ }^{1}$, Lucia Pozo ${ }^{2}$, Alfredo Blanes ${ }^{3}$ and Salvador J Diaz-Cano ${ }^{3,4}$ \\ ${ }^{1}$ Department of Histopathology, Barts and The London Hospitals, London, UK; ${ }^{2}$ Department of Dermatology, \\ Homerton University Hospital, London, UK; ${ }^{3}$ Department of Pathology, University of Malaga School of \\ Medicine, Malaga, Spain and ${ }^{4}$ Department of Histopathology, King's College Hospital and King's College \\ London School of Medicine, London, UK
}

\begin{abstract}
Atypical (dysplastic) melanocytic nevi are clinically heterogeneous malignant melanoma precursors, for which no topographic analysis of cell kinetic, cell cycle regulators and microsatellite profile is available. We selected low-grade atypical melanocytic nevi (92), high-grade atypical melanocytic nevi (41), melanocytic nevi (18 junctional, 25 compound) and malignant melanomas (16 radial growth phase and 27 vertical growth phase). TP53, CDKN2A, CDKN1A, and CDKN1B microsatellite patterns were topographically studied after microdissection; Ki-67, TP53, CDKN2A, CDKN1A, and CDKN1B expressions and DNA fragmentation by in situ end labeling for apoptosis were topographically scored. Results were statistically analyzed. A decreasing junctional-dermal marker expression gradient was observed, directly correlating with atypical melanocytic nevus grading. High-grade atypical melanocytic nevi revealed coexistent TP53-CDKN2A-CDKN1B microsatellite abnormalities, and significantly higher junctional Ki67-TP53 expression (inversely correlated with CDKN1A-CDKN1B expression and in situ end labeling). Malignant melanomas showed coexistent microsatellite abnormalities (CDKN2A-CDKN1B), no topographic gradient, and significantly decreased expression. Melanocytic nevi and low-grade atypical melanocytic nevi revealed sporadic junctional CDKN2A microsatellite abnormalities and no significant topographic kinetic differences. High-grade atypical melanocytic nevi accumulate junctional TP53-CDKN1A-CDKN1B microsatellite abnormalities, being progression TP53-independent and better assessed in the dermis. Melanocytic nevi and low-grade atypical melanocytic nevi show low incidence of microsatellite abnormalities, and kinetic features that make progression unlikely.

Modern Pathology (2011) 24, 471-486; doi:10.1038/modpathol.2010.143; published online 18 February 2011
\end{abstract}

Keywords: atypical melanocytic nevus; cell cycle regulator; kinetics; microsatellite; progression; topographic heterogeneity

Neoplastic transformation is a multistep process, which in certain locations correlates with progressive morphological changes. ${ }^{1}$ Atypical (dysplastic) melanocytic nevi are considered to be the intermediate step in the continuous process from

Correspondence: Dr SJ Diaz-Cano, MD, PhD, FRCPath, Department of Histopathology, King's College Hospital and King's College London School of Medicine, Denmark Hill, London, Greater London SE5 9RS, UK.

E-mail: sjdiazcano@mac.com

Presented in part as abstracts at the meetings of the United States and Canadian Academy of Pathology in Chicago, IL (2002) and Denver (2008).

Received 19 July 2009; revised 13 May 2010; accepted 17 May 2010; published online 18 February 2011 acquired melanocytic nevi to malignant melanoma, ${ }^{2-4}$ which proceeds through radial and vertical growth phases and eventually metastasis. ${ }^{3}$ Although atypical melanocytic nevi reveal progressive morphological changes, ${ }^{5}$ the grading system is controversial and its prognostic relevance is not fully established.

The evolution of neoplasms occurs as a result of the progressive and convergent selection of cell populations, which is a direct expression of the cell kinetics segregation process by either increased proliferation or abnormally low cell loss, resulting in tissue growth. ${ }^{6-8}$ Selective kinetic advantages contribute to dominant growth ${ }^{9-12}$ and are mainly regulated at the restriction point by TP53, pRB, and 


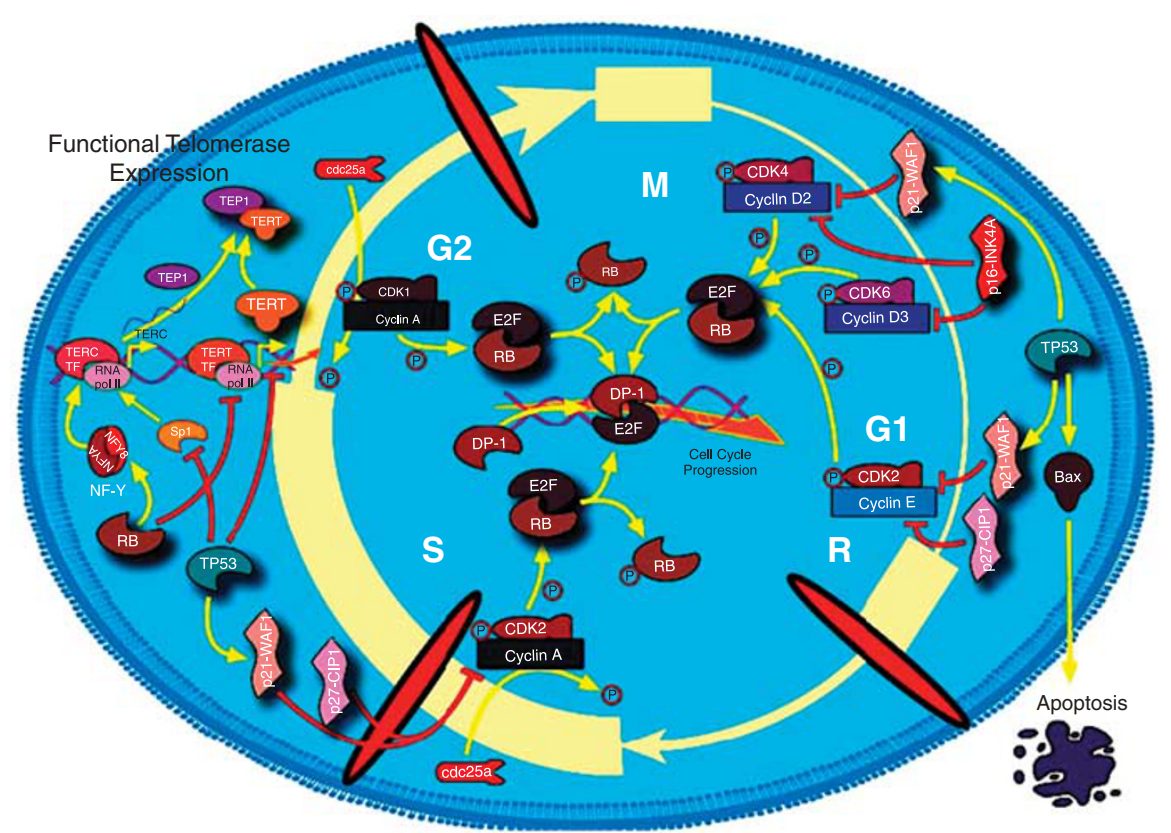

Figure 1 The role of TP53, RB1, and cyclin-dependent kinase inhibitor in regulating the $\mathrm{G}_{1}-\mathrm{S}$ transition, apoptosis, and telomerase expression (both RNA component (TERC) and reverse transcriptase (TERT)).

cyclin-dependent kinase inhibitors (Figure 1), ${ }^{13}$ where a maintained $\mathrm{G}_{1}$ arrest will lead to apoptosis only if pRB is not functional., ${ }^{1,14}$

Genetic lesions within all cells imply a common progenitor contributing that mutation,,$^{9,15,16}$ and it has been found to be associated with loss of heterozygosity of certain loci. ${ }^{7,17}$ The DNA deletions of a given genetic marker should be linked to the loss of tumor suppressor genes, ${ }^{15,16}$ which also contribute to the multistep carcinogenesis process selecting those cells with growth advantages. ${ }^{9}$ A monoclonal tumor origin is supported by concordant tumor suppressor gene abnormalities, ${ }^{7,17,18}$ which have been found to be associated with the loss of heterozygosity of certain loci. The coexistence of several genetic abnormalities and intratumor heterogeneity would be the expression of either tumor cell selection or a simple passive byproduct of genetic instability. ${ }^{19,20}$ However, the association of multiple genetic alterations would become statistically less probable as the number of molecular markers increases and is useful to test clonal expansions in tumors. ${ }^{7,18}$ Although genetic abnormalities are probably asymmetrically acquired, there is a correlation with tumor cell topography in both luminal and solid organs, ${ }^{1,19-23}$ which has not been assessed in skin melanocytic lesions. Any potential topographic segregation of tumor cells will influence interpretations of the results, supporting a linear model if progressive grading is parallel to intraepithelial-to-invasive topography of tumor cells.

Multistep tumorigenesis is a widely accepted concept that has been examined both morphologically and genetically, most of the times as part of a linear model. The G1-S transition of the cell cycle and cell survival through telomere/telomerase is a point that shows alterations in almost all kinds of tumors and systems, and it is likely to reveal differential patterns during progression of melanocytic lesions. An analysis by topographic compartments would eventually help to explain the diagnostic features and the topographic cell segregation in atypical (dysplastic) melanocytic lesions. The independent analysis of several cell cycle regulators in separate topographic tumor cell compartments from a series of melanocytic lesions with progressive degree of atypia will offer the opportunity to check the validity of the linear progression in atypical melanocytic lesions.

This study investigates the topographic profile of cell kinetics, telomerase, and the $\mathrm{G}_{1}-\mathrm{S}$ cell cycle regulators (Table 1), based on the immunoexpression and microsatellite analyses of tumor suppressor genes using microdissected tissue samples from atypical melanocytic nevi and the corresponding melanocytic controls. This study aims to study topographic progression and grading in atypical melanocytic nevi.

\section{Materials and methods}

\section{Case Selection and Sampling}

We retrospectively studied 133 consecutive cases of clinically diagnosed atypical melanocytic nevi (53 junctional and 80 compound) in 121 patients from the Barts and The London Hospitals (London, UK) and University Hospital (Malaga, Spain). All specimens were fixed in $10 \%$ buffered formalin, routinely 
Table 1 Telomerase and genes regulating the cell cycle $G_{1}-S$ transition

\begin{tabular}{|c|c|c|c|c|c|}
\hline $\begin{array}{l}\text { Approved } \\
\text { gene symbol }\end{array}$ & Approved gene name & Location & $\begin{array}{l}\text { Sequence } \\
\text { accession } \\
\text { IDs }\end{array}$ & $\begin{array}{l}\text { Previous } \\
\text { symbols }\end{array}$ & Aliases \\
\hline CDKN1A & $\begin{array}{l}\text { Cyclin-dependent kinase } \\
\text { inhibitor 1A (p21, Cip1) }\end{array}$ & $6 p 21.1$ & $\begin{array}{l}\text { U03106 } \\
\text { NM_078467 }\end{array}$ & CDKN1 & $\begin{array}{l}\text { p21, CIP1, WAF1, SDI1, CAP20, } \\
\text { p21CIP1 }\end{array}$ \\
\hline TP53 & $\begin{array}{l}\text { Tumor protein p53 } \\
\text { (Li-Fraumeni syndrome) }\end{array}$ & $17 \mathrm{p} 13.1$ & AF307851 & & p53 \\
\hline$C D K N 1 B$ & $\begin{array}{l}\text { Cyclin-dependent kinase } \\
\text { inhibitor 1B (p27, Kip1) }\end{array}$ & 12p13.1-p12 & AF480891 & & KIP1, P27KIP1 \\
\hline CDKN2A & $\begin{array}{l}\text { Cyclin-dependent kinase inhibitor } \\
2 \mathrm{~A} \text { (melanoma, p16, inhibits CDK4) }\end{array}$ & $9 p 21$ & L27211 & NM_000077 & $\begin{array}{l}\text { CDKN2, MLM, CDK4I, p16, INK4a, } \\
\text { MTS1, CMM2, ARF, p19, p14, INK4, } \\
\text { p16INK4a }\end{array}$ \\
\hline$R B 1$ & $\begin{array}{l}\text { Retinoblastoma } 1 \\
\text { (including osteosarcoma) }\end{array}$ & $13 q 14.2$ & M15400 & OSRC & \\
\hline TERC & Telomerase RNA component & $3 q 26.2$ & $\begin{array}{l}\text { U86046, } \\
\text { AF221907 } \\
\text { NR_001566 }\end{array}$ & & TR, hTR, TRC3, SCARNA19 \\
\hline TERT & Telomerase reverse transcriptase & $5 p 15.33$ & AF015950 & & TRT, TP2, TCS1, hEST2, EST2 \\
\hline
\end{tabular}

processed, serially sectioned, and stained with hematoxylin-eosin (H\&E). All nevi fulfilled the standard definition of atypical melanocytic nevi, showed both architectural and cytologic atypia, and were evaluated histologically by two independent observers (AB and SJD-C), according to standard criteria. Reproducibility data were not recorded. No case had evidence of scarring, incomplete resection precluding adequate evaluation, or features suggesting congenital onset. The clinical records were reviewed for patient age, nevus location, and familial-personal history of atypical-mole syndrome or malignant melanoma.

The grading was evaluated on multiple, H\&Estained, routine sections of the whole lesion. All atypical melanocytic nevi were required to show architectural and cytological atypia (at least one criterion from each group) and were scored according to the number of criteria fulfilled, into low grade, including mild (2-3 criteria) and moderate (4-5 criteria), and high grade or severe (6-7 criteria). The diagnosis of HG-atypical melanocytic nevi required at least one architectural and two cytological variables, with nuclear pleomorphism being an obligatory criterion. ${ }^{5}$ Processing artifacts were found to influence the cohesion of cells in nests (from preserved to diminished), this feature being therefore excluded from the final classification. In case of grading disagreement, the lesions were discussed during simultaneous inspection before final categorization.

Conventional melanocytic nevi (18 junctional, 25 compound) and malignant melanomas (16 radialgrowth-phase malignant melanoma and 27 vertical growth phase) were used as benign and malignant controls of melanocytic proliferations. The growth phase of malignant melanoma was defined according to standard criteria. ${ }^{3}$

\section{TSG Microsatellite Analysis}

DNA was extracted from the most cellular areas of junctional, superficial, and deep compartments, ${ }^{17,20,23,24}$ after microdissecting at least 100 cells $\left(\sim 0.4 \mathrm{~mm}^{2}\right.$, PixCell II Laser Capture Microdissection, Arcturus Engineering Inc., Mountain View, CA, USA) from two 20- $\mu \mathrm{m}$ unstained paraffin sections/compartment (Figure 1). Appropriate controls (histologically normal epidermis and dermis) and quality assurance (sensitivity, specificity, positive and negative) were run for each test. $^{7,18,25}$

DNA was extracted using a modified phenolchloroform protocol, precipitated with ice-cold absolute ethanol, and resuspended in $10 \mu \mathrm{l}$ of TrisHCl buffer, $\mathrm{pH} 8.4 .^{26}$ DNA was then used for polymerase chain reaction (PCR) amplification of the intron microsatellites of tumor suppressor genes (Table 2). ${ }^{17,20}$ Multiplex PCR was performed using Qiagen ${ }^{\circledR}$ multiplex PCR kit (Qiagen Ltd., West Sussex, UK). Each multiplex PCR reaction included $5 \mu \mathrm{l}$ Qiagen multiplex PCR master mix, $1 \mu \mathrm{l}$ of $10 \times$ primer mix, $2 \mu \mathrm{l}$ distilled water, and $2 \mu \mathrm{l}$ genomic DNA. PCR was performed using a PTC225 (MJ Research) thermocycler. The multiplex PCR protocol was performed using Qiagen Multiplex PCR was performed according to the manufacturer's instructions: an initial step at $95^{\circ} \mathrm{C}$ for $15 \mathrm{~min}$ to activate HotStarTaq DNA polymerase, followed by a three-step cycling of denaturation at $94^{\circ} \mathrm{C}$ for $30 \mathrm{~s}$, annealing at $57^{\circ} \mathrm{C}$ for $90 \mathrm{~s}$, and extension at $72^{\circ} \mathrm{C}$ for $60 \mathrm{~s}$. This was repeated for 35 cycles. A final extension was performed at $60^{\circ} \mathrm{C}$ for $30 \mathrm{~min}$.

A mixture of $0.5 \mu \mathrm{l}$ Genscan 400 ROX HD internal size standard (Applied Biosystems, Foster City, CA, USA) and $18.5 \mu \mathrm{l}$ formamide was added to $1 \mu \mathrm{l}$ of each PCR product. The final mix was heated 
Table 2 Microsatellite markers of cell cycle regulators analyzed

\begin{tabular}{|c|c|c|c|c|}
\hline Marker/gene & Chromosome location & Product size (bp) & $\operatorname{PIC}(\%)$ & Primer sequence \\
\hline \multicolumn{5}{|l|}{ Mix 1} \\
\hline D6S2213/CDKN1A & $6 \mathrm{p} 21.1-21.2$ & $140-160$ & 67.5 & $\begin{array}{l}\text { F: AATAGAGCTCCAGCTTCAGTGa } \\
\text { R: AGACTGAGACCCTGTCTCTGA }\end{array}$ \\
\hline D12S364/CDKN1B & 12p13.1-p12.3 & 277 & 87.0 & $\begin{array}{l}\text { F: CCCCTGGAAGTCCCATC } \\
\text { R: CAGTCCTGAACAGGC }\end{array}$ \\
\hline D9S1749/CDKN2A & $9 p 22$ & $120-160$ & 94.0 & $\begin{array}{l}\text { F: AGGAGAGGGTACGCTTGCAA }{ }^{\mathrm{c}} \\
\text { R: TACAGGGTGCGGGTGCAGATAA }\end{array}$ \\
\hline \multicolumn{5}{|l|}{$\operatorname{Mix} 2$} \\
\hline D9S171/CDKN2A & $9 p 21$ & $159-177$ & 80.0 & $\begin{array}{l}\text { F: AGCTAAGTGAACCTCATCTCTGTCT } \\
\text { R: ACCCTAGCACTGATGGTATAGTCT }\end{array}$ \\
\hline $\mathrm{D} 13 \mathrm{~S} 127 / R B 1$ & 13q12.2-q14.1 & $130-142$ & 60.0 & $\begin{array}{l}\text { F: CAGATATGTACTCATGCACATG } \\
\text { R: AAACAAATGAGTTTGGCTGT }\end{array}$ \\
\hline D17S520/TP53 & $17 \mathrm{p} 12$ & $130-144$ & 85.0 & $\begin{array}{l}\text { F: GGAGAAAGTGATACAAGGGA }{ }^{\mathrm{b}} \\
\text { R: TAGTTAGATTAATACCCACC }\end{array}$ \\
\hline \multicolumn{5}{|l|}{ Mix 3} \\
\hline D12S77/CDKN1B & 12p13.2-p13.1 & $163-193$ & 88.0 & $\begin{array}{l}\text { F: GAAGGGCAACAACAGTGAA }{ }^{a} \\
\text { R: CTTTTTTTTCTCCCCCACTC }\end{array}$ \\
\hline $\mathrm{D} 13 \mathrm{~S} 137 / R B 1$ & $13 q 14.4$ & 113-135 & 84.0 & $\begin{array}{l}\text { F: CAGGAGGGATGGACTCACTTCa } \\
\text { R: TTTCCTCATTCTTTCCCAATTG }\end{array}$ \\
\hline
\end{tabular}

Primer sequences for all these microsatellite markers are available at the Genome database (http://www.gdb.org). Primers were provided by Sigma-Genosys Ltd. Each forward primer was 5'-labeled using amidite-labeling chemistry. The fluorescent labels were 6FAM (superscript 'b'), HEX (superscript 'c') and TAMARA (superscript 'a') (ABI3700, filter set D). Primers were re-suspended in TE buffer in three stock mixes (100 $\mu$ M) that were prediluted in $10 \times$ primer mix $(2 \mu \mathrm{M}$ of each primer in TE buffer).

${ }^{\mathrm{a}}$ TAMARA

${ }^{\mathrm{b}} 6 F A M$.

${ }^{\mathrm{c}} H E$.

for $5 \mathrm{~min}$ at $95^{\circ} \mathrm{C}$ to denature double-stranded DNA prior to genotyping. The fluorescent PCR products were subsequently fractionated on a capillary-based laser-activated ABI PRISM ${ }^{\circledR} 3700$ (Applied Biosystems), and analyzed (size and peak high) using ABI Genotyper 3.7 software (Applied Biosystems).

Interpretation and inclusion criteria in each sample included the following: (a) Allelic imbalance showed evidence of loss of heterozygosity when allele ratios were $\geq 4: 1$ in any tumor suppressor gene; otherwise retention of heterozygosity was assigned. ${ }^{7,18,20,24,27,28}$ This ratio represents $80 \%$ of clonal cells in the sample and hence was used to increase the detection specificity. ${ }^{7}$ (b) Additional allele bands present in tumor samples but not in the corresponding controls were considered as evidence of somatic microsatellite abnormalities. ${ }^{7,19,20,29}$

\section{Immunohistochemical Detection of Ki-67, Cell Cycle Regulators, and TERT}

Sections were mounted on positively charged slides (Superfrost Plus, Fisher Scientific, Fair Lawn, NJ, USA), baked at $60^{\circ} \mathrm{C}$ for $2 \mathrm{~h}$, and processed as described. ${ }^{22,24,30}$ After routine dewaxing and rehydration, endogenous peroxidase quenching, and antigen heat retrieval, the slides were transferred to a moist chamber. Nonspecific binding was blocked with polyclonal horse serum and sections incubated with monoclonal primary antibodies (Table 3). Then sections were serially incubated with biotinylated antimouse antibody, and peroxidase-labeled avidin-biotin complex. The reaction was developed under microscopic control, using 3,3'-diaminobenzidine tetrahydrochloride with $0.3 \% \mathrm{H}_{2} \mathrm{O}_{2}$ as chromogen (Sigma, St Louis, MO, USA), and the sections counterstained with hematoxylin. Both positive (reactive lymph node) and negative (omitting the primary antibody) controls were simultaneously run.

\section{In Situ Hybridization for Telomerase RNA Component (TERC)}

Oligonucleotide probes were generated by Primer3 software available free at http://frodo.wi.mit.edu/ cgi-bin/primer3/primer3_www.cgi, using the TERT catalytic domain sequence from NCBI GenBank. Antisense oligonucleotide probes (5'-CGTTCCTC TTCCTGCGGCCTG-3' ${ }^{\prime}$ complementary to nt 360381, and 5'-CCTCAGTTAGGGTTAGACAAAAAAT GGCCAC-3' complementary to nt 31-60, obtained from Operon Europe, Cologne, Germany), sense probe (5'-GTGGCCATTTTTTGTCTAACCCTAACTG AG-3' from nt 31-60, Operon Europe), and control oligonucleotide (30mer, 5'-TTPGGTAACGCCAGGG TTTTCCCAGTCACG-OH-3', provided by Roche Diagnostics GmbH, Mannheim, Germany) were 3'labeled using DIG Oligonucleotide tailing kit (Roche Diagnostics), TdT and a mixture of digoxigeninlabeled dideoxyuridine-triphosphate, and 2'-deoxyadenosine $5^{\prime}$-triphosphate (dATP), according to the manufacturer's recommendations. The reagents 
Table 3 Primary antibodies used in the immunohistochemical study

\begin{tabular}{|c|c|c|c|c|c|c|}
\hline Antibody & Source & Dilution & $\begin{array}{l}\text { Epitope } \\
\text { retrieval }\end{array}$ & $\begin{array}{l}\text { Positive } \\
\text { control }\end{array}$ & $\begin{array}{l}\text { Staining } \\
\text { pattern }\end{array}$ & Internal control \\
\hline $\begin{array}{l}\text { Ki67 (mouse monoclonal } \\
\text { antibody, clone MM1) } \text { IgG }_{1}\end{array}$ & $\begin{array}{l}\text { Novocastra } \\
\text { Laboratories Ltd., } \\
\text { Newcastle upon- } \\
\text { Tyne, UK }\end{array}$ & $1: 300$ & $\begin{array}{l}\text { Pressure } \\
\text { cooker }\end{array}$ & Appendix & Nuclear & $\begin{array}{l}\text { Proliferating cells in the basal } \\
\text { epidermis and hair follicles }\end{array}$ \\
\hline $\begin{array}{l}\text { p53 (mouse monoclonal } \\
\text { antibody, clone DO-7 ) } \operatorname{IgG}_{2 \mathrm{~b} \kappa}\end{array}$ & Dako, Denmark & $1: 90$ & $\begin{array}{l}\text { Pressure } \\
\text { cooker }\end{array}$ & $\begin{array}{l}\text { Known colon } \\
\text { cancer or basal } \\
\text { cell carcinoma }\end{array}$ & Nuclear & $\begin{array}{l}\text { Occasional sun-damaged } \\
\text { keratinocytes }\end{array}$ \\
\hline $\begin{array}{l}\text { p21 (mouse monoclonal } \\
\text { antibody, clone EA10) } \operatorname{IgG}_{1 \kappa}\end{array}$ & $\begin{array}{l}\text { Oncogene } \\
\text { Research } \\
\text { Products, Boston, } \\
\text { MA, USA }\end{array}$ & $1: 30$ & $\begin{array}{l}\text { Pressure } \\
\text { cooker }\end{array}$ & Appendix & Nuclear & $\begin{array}{l}\text { Suprabasal keratinocytes, } \\
\text { sebocytes, inner root sheath } \\
\text { of hair follicles }\end{array}$ \\
\hline $\begin{array}{l}\text { p27 (mouse monoclonal } \\
\text { antibody, clone 1B4) } \operatorname{IgG}_{2 a}\end{array}$ & $\begin{array}{l}\text { Novocastra } \\
\text { Laboratories Ltd. }\end{array}$ & $1: 40$ & $\begin{array}{l}\text { Pressure } \\
\text { cooker }\end{array}$ & Tonsil & Nuclear & $\begin{array}{l}\text { Upper layers of epidermis, } \\
\text { sebocytes, inner root sheath } \\
\text { of hair follicles }\end{array}$ \\
\hline $\begin{array}{l}\text { p16 (mouse monoclonal } \\
\text { antibody, clone F-12) } \operatorname{IgG}_{2 \mathrm{a}}\end{array}$ & $\begin{array}{l}\text { Santa Cruz } \\
\text { Biotechnology Inc. }\end{array}$ & $1: 300$ & $\begin{array}{l}\text { Pressure } \\
\text { cooker }\end{array}$ & $\begin{array}{l}\text { Conventional } \\
\text { nevus }\end{array}$ & $\begin{array}{l}\text { Nuclear and } \\
\text { cytoplasmic }\end{array}$ & $\begin{array}{l}\text { Epidermal keratinocytes, hair } \\
\text { follicles, adnexal glands, and } \\
\text { in dermal inflammatory cells }\end{array}$ \\
\hline $\begin{array}{l}p R b 1 \text { (mouse monoclonal } \\
\text { antibody, clone IF8) IgG } 1\end{array}$ & $\begin{array}{l}\text { Santa Cruz } \\
\text { Biotechnology Inc. }\end{array}$ & $1: 100$ & $\begin{array}{l}\text { Pressure } \\
\text { cooker }\end{array}$ & $\begin{array}{l}\text { Known } \\
\text { melanoma }\end{array}$ & Nuclear & $\begin{array}{l}\text { Keratinocytes at the upper } \\
\text { half of the epidermis and } \\
\text { inner root sheath of hair } \\
\text { follicles }\end{array}$ \\
\hline $\begin{array}{l}\text { Telomerase RT subunit } \\
\text { (mouse monoclonal } \\
\text { antibody, clone } 44 \mathrm{~F} 12 \text { ) } \operatorname{IgG}_{2 \mathrm{a}}\end{array}$ & $\begin{array}{l}\text { Novocastra } \\
\text { Laboratories Ltd }\end{array}$ & $1: 50$ & Microwave & Normal testis & $\begin{array}{l}\text { Nucleolar/ } \\
\text { nuclear }\end{array}$ & $\begin{array}{l}\text { Basal keratinocytes, hair } \\
\text { follicles, and scattered } \\
\text { lymphocytes }\end{array}$ \\
\hline
\end{tabular}

were mixed and centrifuged briefly for $2 \mathrm{~min}$, then incubated for $15 \mathrm{~min}$ at $37^{\circ} \mathrm{C}$ and subsequently placed on ice. The reaction was stopped by adding $2 \mu \mathrm{l}$ of $0.2 \mathrm{M}$ EDTA (pH 8.0). The labeled oligonucleotide was not precipitated thereafter.

Paraffin sections $(5 \mu \mathrm{m})$ were cut onto Superfrost slides (Merck). Sections were deparaffinized, microwaved in pre-warmed $10 \%$ citrate buffer $(10 \mathrm{~min})$, and pre-hybridized at $42^{\circ} \mathrm{C}$. Following this, the sections were hybridized with $40 \mathrm{ng} / \mu \mathrm{l}$ of digoxigenin-labeled probe in a pre-hybridization buffer containing dextran sulfate overnight at $42^{\circ} \mathrm{C}$ using a Hybaid Omnislide machine. Following stringency washes to $0.1 \times$ SCC $/ 50 \%$ formamide, sections were stained with anti-digoxigenin-AP Fab fragments. After washing, the sections were developed with nitroblue tetrazolium chloride/bromo-chloro-idolyphosphate (Sigma) chromagen solutions. Stained sections were scored for the intensity of the nuclear mRNA signal. Nuclear and cytoplasmic staining was recorded separately. The slides were counterstained in hematoxylin, coverslipped, and examined under a light microscope. Clearly visualized, finely granular, or tiny dot-like brown stains were considered as positive signals. Far less intense or unequivocal stains that are usually seen in a diffuse manner were regarded as background noise.

Sections were stained on two separate occasions and the results analyzed by two independent observers (EAH and SJD-C). There was $<5 \%$ variation between sections and observers. Sections of human testicular tissue were used as positive control. The sense probe was used as negative control.

\section{In Situ End Labeling of Fragmented DNA}

Extensive DNA fragmentation associated with apoptosis was detected by in situ end labeling as reported..$^{31,32}$ After routine dewaxing and hydration, the sections were incubated in $2 \times$ standard saline citrate $\left(20 \mathrm{~min}\right.$ at $\left.80^{\circ} \mathrm{C}\right)$ and digested with pronase $(500 \mu \mathrm{g} / \mathrm{ml}, 25 \mathrm{~min}$, room temperature) in a moist chamber.

DNA fragments were labeled on $5^{\prime}$-protruding termini by incubating the sections with the Klenow fragment of Escherichia coli DNA polymerase I $(20 \mathrm{U} / \mathrm{ml}$ in $50 \mathrm{mmol} / \mathrm{l}$ Tris-HCl, $\mathrm{pH} 7.5,10 \mathrm{mmol} / \mathrm{l}$ $\mathrm{MgCl}_{2}, 1 \mathrm{mmol} / \mathrm{l}$ DTT, $250 \mu \mathrm{g} / \mathrm{ml}$ bovine serum albumin, $5 \mu \mathrm{M}$ each of dATP, dCTP, dGTP, as well as $3.25 \mu \mathrm{mol} / \mathrm{l} \mathrm{dTTP}$, and $1.75 \mu \mathrm{mol} / \mathrm{l}$ 11-digoxigenindUTP), at $37^{\circ} \mathrm{C}$ in a moist chamber. The incorporated digoxigenin-dUMPs were immunoenzymatically detected by using anti-digoxigenin Fab fragments labeled with alkaline phosphatase $(7.5 \mathrm{U} / \mathrm{ml}$, in $100 \mathrm{mmol} / \mathrm{l}$ Tris-HCl, $\mathrm{pH}$ 7.6, $150 \mathrm{mmol} / \mathrm{l} \mathrm{NaCl}, 1 \%$ bovine serum albumin) for $4 \mathrm{~h}$ at room temperature. The reactions were developed with the mixture of nitroblue tetrazolium-X phosphate in $100 \mathrm{mmol} / \mathrm{l}$ Tris-HCl (pH 9.5), $100 \mathrm{mmol} / \mathrm{l} \mathrm{NaCl}$, and $50 \mathrm{mmol} / \mathrm{l}$ $\mathrm{MgCl}_{2}$ under microscopic control. Appropriate controls were simultaneously run, including positive (reactive lymph node), negative (same conditions omitting DNA polymerase I), and enzymatic (DNase I digestion before end labeling). The enzymatic controls were used to reliably establish the positivity threshold in each sample. 


\section{Quantification of Positive Nuclei and Statistical Analysis}

At least $50 \mathrm{HPFs}\left(7.6 \mathrm{~mm}^{2}\right)$ were screened in each pathological group, beginning with the most cellular area. The number of positive nuclei was expressed per HPF and per 1000 tumor cells, and the average and standard deviation (s.d.) calculated in each pathological condition and patient as described. ${ }^{23,24,32,33}$ The positivity threshold was experimentally established at the positive control in each staining batch. Only nuclei with staining features similar to those of their corresponding positive control were considered positive for any marker.

All variables were compared by diagnostic groups and topographic compartments. The normality of quantitative variables was tested by KolmogorovSmirnoff test and then analyzed by Kruskal-Wallis test (more-than-two-group comparisons) or MannWhitney test (two-group comparisons) for nonparametric variables and Student's $t$-tests for normal variables. The application of non-parametric statistics is more powerful than any centralization analysis based on variables with normal distribution. These non-parametric tests are less intuitive, but more effective in highlighting the statistical differences based on distribution, number of cases in each group, skewness, and variance within and between the groups.

Qualitative variables were compared using chi-square tests and Fisher's exact tests with Yates correction when needed. Differences were considered significant if $P<0.05$ in two-tailed distributions.

\section{Results}

Atypical melanocytic nevi were found in 65 women and 46 men, mean age $36.56 \pm 11.94$ years, being mainly located in the extremities and trunk (Table 4). All nevi met the criteria proposed for atypical melanocytic nevi, ${ }^{34,35}$ and comprised 43 junctional and 80 compound melanocytic nevi, graded atypical melanocytic nevi-mild in 31 (25\%), atypical melanocytic nevi-moderate in $61(50 \%)$, and atypical melanocytic nevi-severe in $31(25 \%)$, classified according to the criteria shown in Table 5. A topographic gradient was observed from junctional to dermal compartments for all markers in all melanocytic lesions, the values being higher in malignant than in benign lesions. The gradient was decreasing for Ki-67, TERT, TERC, TP53, CDKN1A, and pRB1 and increasing for in situ end labeling, $C D K N 1 B$, and $C D K N 2 A$ (Figures 2 and 3). Although the variability is a factor that can make the interpretation of results more difficult, partially due to the degree of overlapping between groups, it does not make the results invalid per se. Variables like the mitotic figure counting can reveal a high standard deviation in certain malignancies (ie, adrenal cortical carcinomas) and for that reason we cannot conclude that it is not informative (in fact it may represent the single most useful variable for the diagnosis, like in adrenal cortical carcinomas).

\section{Atypical Melanocytic Nevus Grading}

There were no statistically significant differences between atypical melanocytic nevi-mild and atypical melanocytic nevi-moderate in any of the variables and compartments except for CDKN1A. The highest $C D K N 1 A$ expression was observed in the dermal compartment of atypical melanocytic nevi-moderate. Therefore, the statistical analysis was performed by comparing low-grade (mild and moderate) and high-grade (severe) dysplasia. Significant differences were observed in all the studied markers, in one or more compartments except for

Table 4 Age, sex distribution, and location of melanocytic lesions

\begin{tabular}{|c|c|c|c|c|c|c|}
\hline & $J M N$ & $C M N$ & $L G-A M N$ & $H G-A M N$ & $M M-R G P$ & $M M-V G P$ \\
\hline Number of specimens & 18 & 25 & 87 & 34 & 16 & 25 \\
\hline Number of patients & 16 & 23 & 78 & 34 & 16 & 25 \\
\hline \multicolumn{7}{|l|}{ Age } \\
\hline Mean & 33.60 & 33.13 & 35.13 & 43.29 & 55.53 & 63.30 \\
\hline Range & $21-61$ & $6-71$ & $7-82$ & $26-66$ & $26-85$ & $25-86$ \\
\hline Sex ratio (M:F) & $6: 10$ & $10: 13$ & $29: 49$ & $10: 24$ & $7: 9$ & $10: 15$ \\
\hline \multicolumn{7}{|l|}{ Location } \\
\hline Extremities & 7 & 6 & 37 & 21 & 5 & 10 \\
\hline Trunk & 10 & 15 & 42 & 9 & 8 & 7 \\
\hline Head and neck & 0 & 1 & 0 & 2 & 1 & 7 \\
\hline NM & 1 & 3 & 8 & 2 & 2 & 1 \\
\hline
\end{tabular}

Abbreviations: CMN, compound melanocytic nevi; HG-AMN, high-grade atypical melanocytic nevi; JMN, junctional melanocytic nevi; LG-AMN, low-grade atypical melanocytic nevi; MM-RGP, malignant melanoma, radial growth phase; MM-VGP, malignant melanoma, vertical growth phase; NM, not mentioned. 
Table 5 Major criteria for grading atypical (dysplastic) melanocytic nevi (AMN) ${ }^{\mathrm{a}}$

\begin{tabular}{|c|c|c|c|c|}
\hline Variables & $A M N-$ mild, $n(\%)$ & AMN-moderate, $n(\%)$ & $A M N$-severe, $n(\%)$ & Significance \\
\hline \multicolumn{5}{|l|}{ Junctional pattern ${ }^{\mathrm{b}}$} \\
\hline Lentiginous & $8(7)$ & $29(23)$ & $13(11)$ & $P<0.000001$ \\
\hline Nested & $22(18)$ & $28(23)$ & $4(3)$ & \\
\hline Mixed & $1(1)$ & $4(3)$ & $14(11)$ & \\
\hline \multicolumn{5}{|l|}{ Suprabasal melanocytes ${ }^{\mathrm{b}}$} \\
\hline Nest only & $2(2)$ & $9(7)$ & $2(2)$ & $P<0.000001$ \\
\hline Nest and lentiginous hyperplasia & $1(1)$ & $5(4)$ & $26(21)$ & \\
\hline Non-applicable & $28(23)$ & $47(38)$ & $3(2)$ & \\
\hline \multicolumn{5}{|l|}{ Nuclear pleomorphism ${ }^{\mathrm{b}}$} \\
\hline Slight & $31(25)$ & $38(31)$ & $0(0)$ & $P<0.000001$ \\
\hline Prominent & $0(0)$ & $23(19)$ & $31(25)$ & \\
\hline \multicolumn{5}{|l|}{ Chromatin pattern } \\
\hline Thin & $26(21)$ & $50(41)$ & $11(10)$ & $P=0.000002$ \\
\hline Granular & $5(4)$ & $11(10)$ & $20(16)$ & \\
\hline \multicolumn{5}{|l|}{ Nucleolus } \\
\hline Inconspicuous & $21(17)$ & $28(23)$ & $7(6)$ & $P=0.000845$ \\
\hline Prominent & $10(8)$ & $33(27)$ & 24 (19) & \\
\hline \multicolumn{5}{|l|}{ Histological regression } \\
\hline No & $4(3)$ & $9(7)$ & $25(20)$ & \\
\hline Yes & $26(21)$ & $53(44)$ & $6(5)$ & \\
\hline
\end{tabular}

${ }^{\mathrm{a} C e l l s}$ with bold numbers represent actual frequency significantly different from the expected range.

${ }^{\mathrm{b}}$ Features that distinguished $\mathrm{AMN}-$ mild from $\mathrm{AMN}-$ moderate.

TERC. Differences were predominantly observed in the junctional compartment, with a minor contribution from the dermal compartment.

The low-grade $\rightarrow$ high-grade transition of atypical (dysplastic) melanocytic lesions revealed an increase of proliferation and telomerase expression and decrease of apoptosis at both junctional and dermal compartments. The junctional compartment showed increasing expression for TP53, CDKN1A, and $R B 1$, along with decreasing expression of $C D K N 2 A$ and $C D K N 1 B$, whereas the dermal compartment revealed increasing expression for TP53, $C D K N 2 A$, and $R B 1$, along with decreasing expression of $C D K N 1 A$ and $C D K N 1 B$ (Figure 4). At the expression level, $C D K N 1 B$ revealed statistically significant differences at both junctional and dermal compartments, and TP53, RB1, and CDKN2A were found to be statistically different at the junctional compartment only. At the microsatellite level, CDK1A was found to be statistically significant at the junctional compartment, while TP53, RB1, and $C D K N 1 B$ showed statistically significant differences at the dermal compartment.

\section{Microsatellite Profile of Cell Cycle Regulators}

Microsatellite abnormalities were significantly more frequent in junctional than in dermal compartments, predominating in melanocytic lesions with high nuclear grade (Figures 3 and 4). Coexistent microsatellite abnormalities characterized malignant lesions, in particular vertical-growth-phase malignant melanomas, and the lowest incidence of microsatellite abnormalities was present in the dermal compartments of the melanocytic nevus.

The differential comparative pattern was variable, $C D K N 1 B$ being the marker that discriminated more melanocytic lesions using the microsatellite profile, in particular in the dermal compartments (Figure 3). Only $C D K N 1 B$ distinguished low-grade and benign lesions, while among high-grade lesions verticalgrowth-phase malignant melanomas stood as significantly different from both HG-atypical melanocytic nevi and radial-growth-phase malignant melanomas. The distinction between LG-atypical melanocytic nevi and HG-atypical melanocytic nevi was better made in the dermal compartment using $T P 53, R B 1$, and $C D K N 1 B$, whereas only junctional $C D K N 1 A$ distinguished LG-atypical melanocytic nevi from HG-atypical melanocytic nevi.

\section{Discussion}

High-grade atypical melanocytic nevi accumulate predominantly junctional microsatellite abnormalities of TP53 and cell cycle regulators (CDKN1A and $C D K N 1 B$ ), along with abnormal p53 expression; progression is better assessed by cell cycle regulator expression in dermal compartments and is TP53independent. Melanocytic nevi and low-grade atypical melanocytic nevi show low incidence of cell cycle regulator abnormalities, and kinetic features 


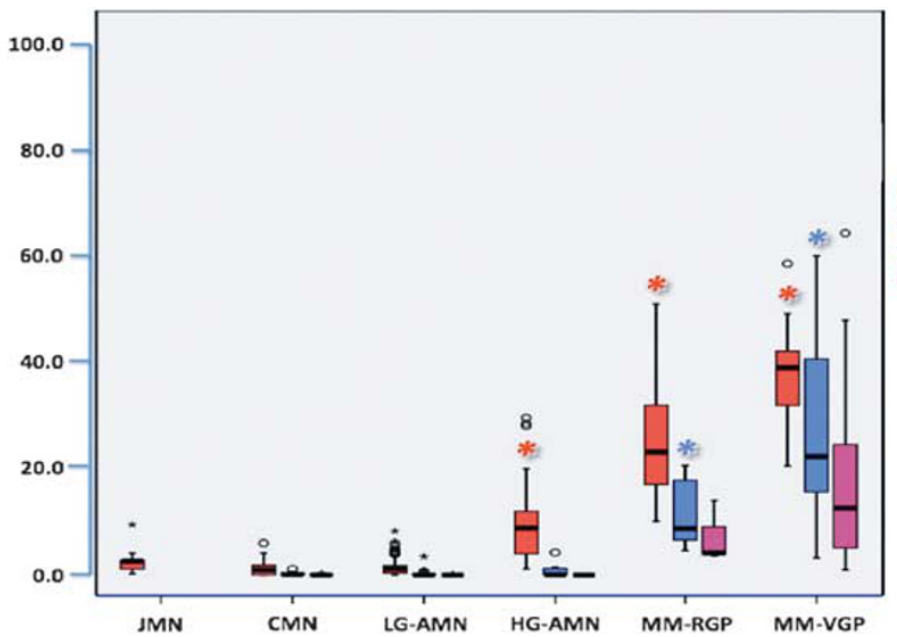

\section{Junctional}

Superficial dermal

Deep dermal

Statistically significant

* Junctional

* superficial dermal

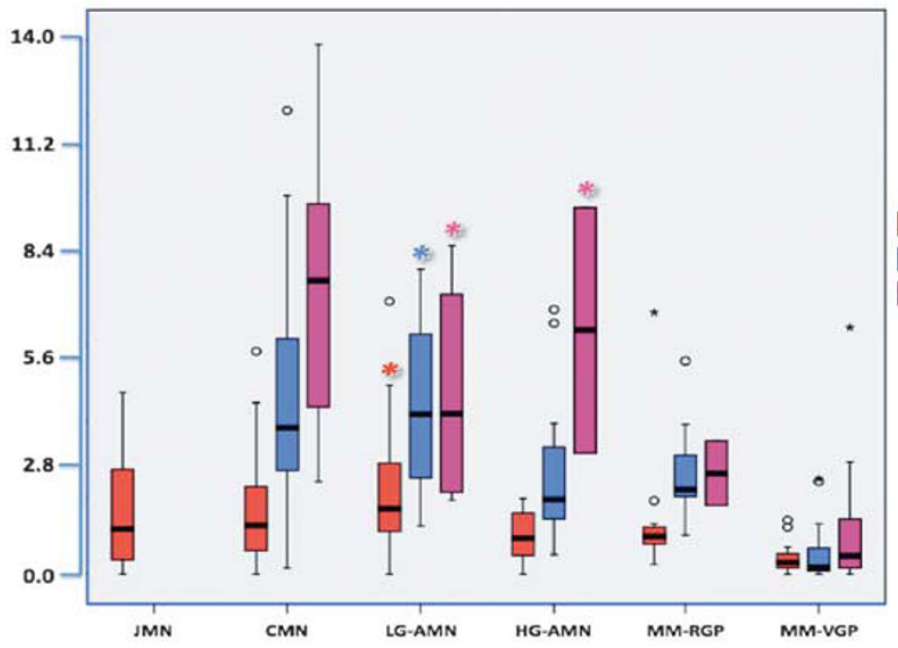

ISEL

Junctional

Superficial dermal

Deep dermal

Statistically significant

* Junctional

* superficial dermal

* Deep dermal!

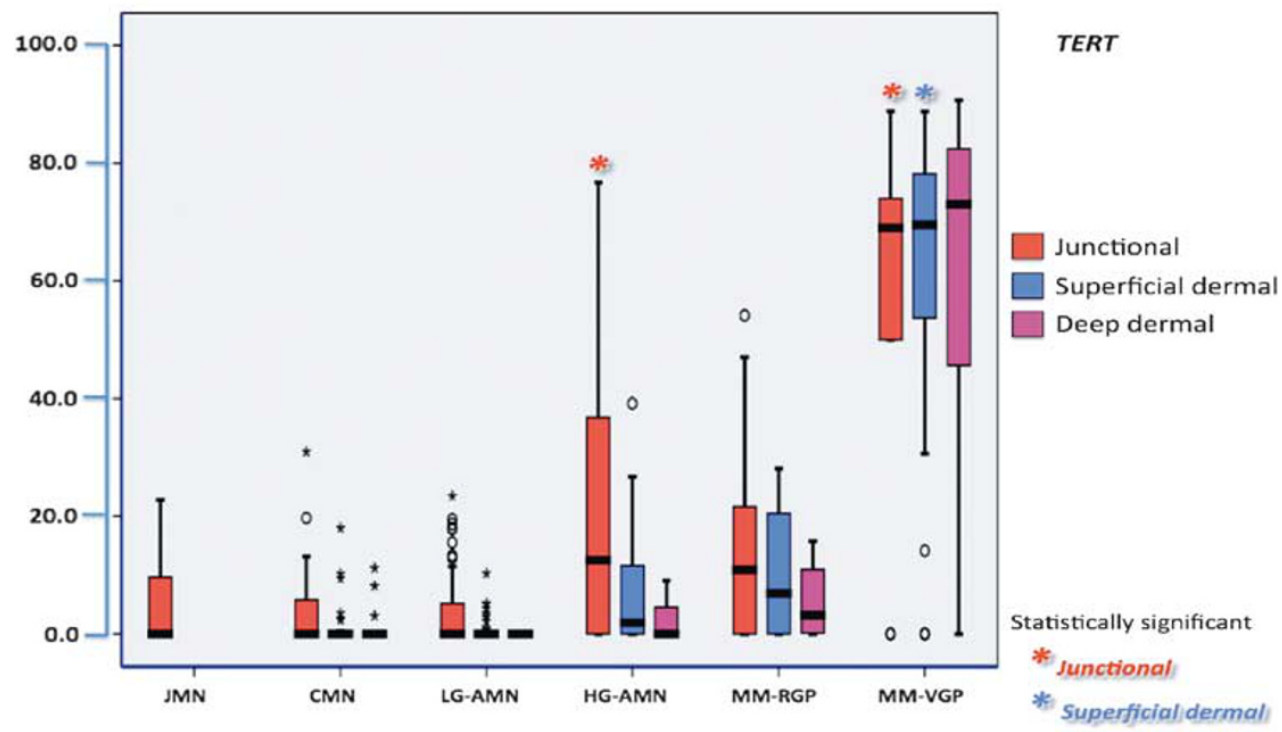

that make progression unlikely. As cell topography has not been assessed systematically before in melanocytic lesions, no reference values are available for comparison. For this reason, this discussion mainly focuses on the explanation or biological meaning of the results presented above.

Grading and topographic analyses segregate out non-progressive low-grade dysplastic nevi from true 
Figure 2 Ki-67 proliferation index (no. of positive nuclei/HPF). High-grade atypical melanocytic nevi showed significantly higher junctional Ki-67 index than low-grade atypical melanocytic nevi, compound melanocytic nevi, and junctional melanocytic nevi $(P<0.05$ in all groups), whereas there were no significant differences in the Ki-67 index between low-grade atypical melanocytic nevi and compound melanocytic nevi. Ki-67 levels were significantly higher in all radial-growth-phase and vertical-growth-phase malignant melanoma compartments than in the corresponding non-malignant compartments $(P<0.05)$. Some vertical-growth-phase malignant melanomas showed focal Ki-67-positive cell clusters at the advancing tumor edge and heterogeneous staining throughout the lesion. In situ end labeling for apoptosis (no. of positive nuclei/HPF). Low-grade atypical melanocytic nevi and high-grade atypical melanocytic nevi showed significantly higher in situ end labeling indices compared with vertical-growth-phase malignant melanomas in all compartments, but only low-grade atypical melanocytic nevi showed significantly higher in situ end labeling index in the junctional compartment. High-grade atypical melanocytic nevi showed significantly lower in situ end labeling levels than low-grade atypical melanocytic nevi. In comparison with compound melanocytic nevi, significant differences were found between the SD compartments in high-grade atypical melanocytic nevi and compound melanocytic nevi, with the highest values seen in compound melanocytic nevi. TERT (no. of positive nuclei/HPF). All melanocytic groups expressed TERT immunoreactivity with nucleolar (majority of cases) or diffuse nuclear pattern with nucleolar enhancement. The junctional and dermal profiles of high-grade atypical melanocytic nevi were similar but significantly higher than those observed in junctional melanocytic nevi (junctional only), compound melanocytic nevi (junctional and SD), and low-grade atypical melanocytic nevi (junctional and SD), but significantly lower than vertical-growth-phase malignant melanomas in all compartments. The low-grade atypical melanocytic nevi group showed no statistically significant differences when compared with junctional melanocytic nevi and compound melanocytic nevi.

malignant melanoma precursors, namely, high-grade atypical melanocytic nevi. These findings support a multistep tumorigenesis and a divergent model of progression as more appropriate than a linear model. A combined topographic and grading stratification of melanocytic lesions offers very useful information on progression: progressive grading parallel to intraepithelial-to-invasive topography of

Figure 3 CDKN1A: Immunoexpression (no. of positive nuclei/HPF). High-grade atypical melanocytic nevi showed significantly higher $C D K N 1 A$ expression than low-grade atypical melanocytic nevi and compound melanocytic nevi $(P<0.5$ in both conditions), but not higher than junctional melanocytic nevi. The $C D K N 1 A$ junctional expression of both low-grade atypical melanocytic nevi and high-grade atypical melanocytic nevi was significantly higher than that of compound melanocytic nevi, but was not significantly different from that of junctional melanocytic nevi. The dermal expression of CDKN1A in low-grade atypical melanocytic nevi and high-grade atypical melanocytic nevi was significantly lower than that in vertical-growth-phase malignant melanomas. In some vertical-growth-phase malignant melanomas, $C D K N 1 \mathrm{~A}$ immunoreactivity was restricted to the most peripheral cells in infiltrating dermal nodules. This pattern was not seen in any other melanocytic proliferation. The microsatellite profile was significantly different at the junctional compartment of high-grade atypical melanocytic nevi and vertical-growth-phase malignant melanomas. TP53: Immunoexpression (no. of positive nuclei/HPF). The highest TP53 expression was observed in vertical-growth-phase malignant melanomas (10.0 \pm 10.7$)$ and was significantly higher than that in the remaining groups $(P<0.01)$. High-grade atypical melanocytic nevi also revealed significantly higher values than in the other groups (junctional melanocytic nevi, compound melanocytic nevi, and low-grade atypical melanocytic nevi). No TP53 immunoreactivity was observed in dermal compartments except for vertical-growth-phase malignant melanomas. The microsatellite profile was significantly different at the junctional compartment of vertical-growth-phase malignant melanomas and the dermal compartment of high-grade atypical melanocytic nevi and vertical-growth-phase malignant melanomas. CDKN1B: Immunoexpression (no. of positive nuclei/HPF). Low-grade atypical melanocytic nevi and high-grade atypical melanocytic nevi expressed significantly higher $C D K N 1 B$ levels than vertical-growth-phase malignant melanomas (in all compartments). Low-grade atypical melanocytic nevi showed significant differences compared with compound melanocytic nevi only (in junctional and SD compartments), while high-grade atypical melanocytic nevi showed significantly lower $C D K N 1 B$ expression than radial-growth-phase malignant melanomas. Junctional and SD compartments of low-grade atypical melanocytic nevi expressed significantly higher $C D K N 1 B$ levels than the corresponding high-grade atypical melanocytic nevi compartments. Malignant melanoma cells in the vicinity of an ulcerating surface or necrotic foci showed higher expression of $C D K N 1 B$; these areas were not included in the final counting procedure. The microsatellite profile was significantly different at the junctional compartment of radial-growth-phase malignant melanomas and vertical-growth-phase malignant melanomas, and the dermal compartment of high-grade atypical melanocytic nevi and vertical-growth-phase malignant melanomas. CDKN2A: Immunoexpression (no. of positive nuclei/HPF). None of the cases of low-grade atypical melanocytic nevi, junctional melanocytic nevi, or compound melanocytic nevi showed complete loss of nuclear $C D K N 2 A$ at the junction. In dermal compartments, all compound high-grade atypical melanocytic nevi cases expressed nuclear $C D K N 2 A$ and only one case (2.17\%) of lowgrade atypical melanocytic nevi lacked nuclear $C D K N 2 A$ staining. The mean values of nuclear $C D K N 2 A$ expression in low-grade atypical melanocytic nevi and high-grade atypical melanocytic nevi were significantly higher than those recorded in radial- and vertical-growthphase malignant melanomas in all compartments. High-grade atypical melanocytic nevi showed statistically significant lower levels of nuclear CDKN2A compared with junctional melanocytic nevi and compound melanocytic nevi (in all compartment). This was also the case when low-grade atypical melanocytic nevi were compared with compound melanocytic nevi in the junctional and SD compartments only. No differences were found between low-grade atypical melanocytic nevi and junctional melanocytic nevi. Both junctional and DD compartments in high-grade atypical melanocytic nevi expressed significantly lower levels of nuclear $C D K N 2 A$ than low-grade atypical melanocytic nevi. The microsatellite profile was significantly different at the junctional compartment of high-grade atypical melanocytic nevi, radial- and vertical-growth-phase malignant melanomas, and at the dermal compartment of vertical-growthphase malignant melanomas. RB1: Immunoexpression (no. of positive nuclei/HPF). Low-grade atypical melanocytic nevi did not show any significant differences compared with junctional melanocytic nevi (junctional compartment) and compound melanocytic nevi (all compartments). This group expressed lower pRb1 levels than radial-growth-phase malignant melanomas (junctional compartment, $P<0.05$ ) and vertical-growth-phase malignant melanomas (all compartments, $P<0.001$ ). High-grade atypical melanocytic nevi revealed a statistically significantly higher expression than compound melanocytic nevi and low-grade atypical melanocytic nevi (at the junctional compartment only). However, the expression levels in the SD and DD compartments were significantly lesser than those in verticalgrowth-phase malignant melanomas. The microsatellite profile was significantly different at the junctional and dermal compartments of vertical-growth-phase malignant melanomas. 


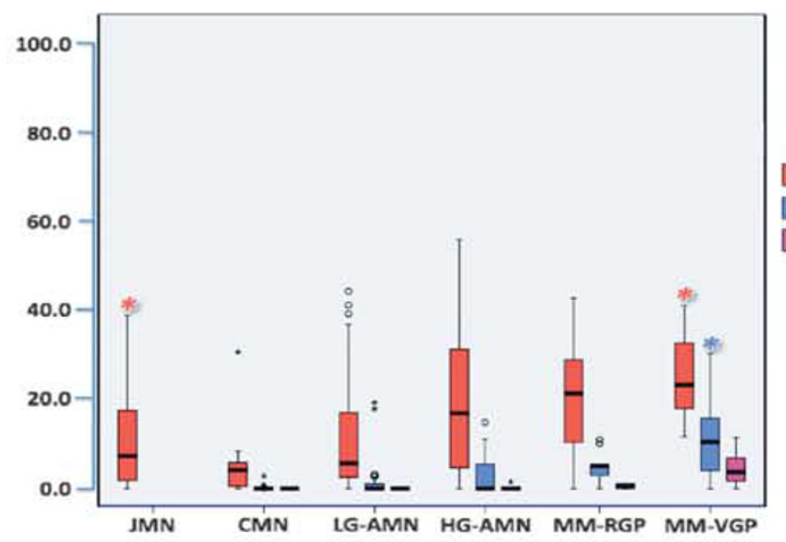

P21 - CDKN1A

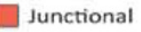

Superficial dermal

$\square$ Deep dermal

Statistically significant

* Junctional

* Superficial dermal
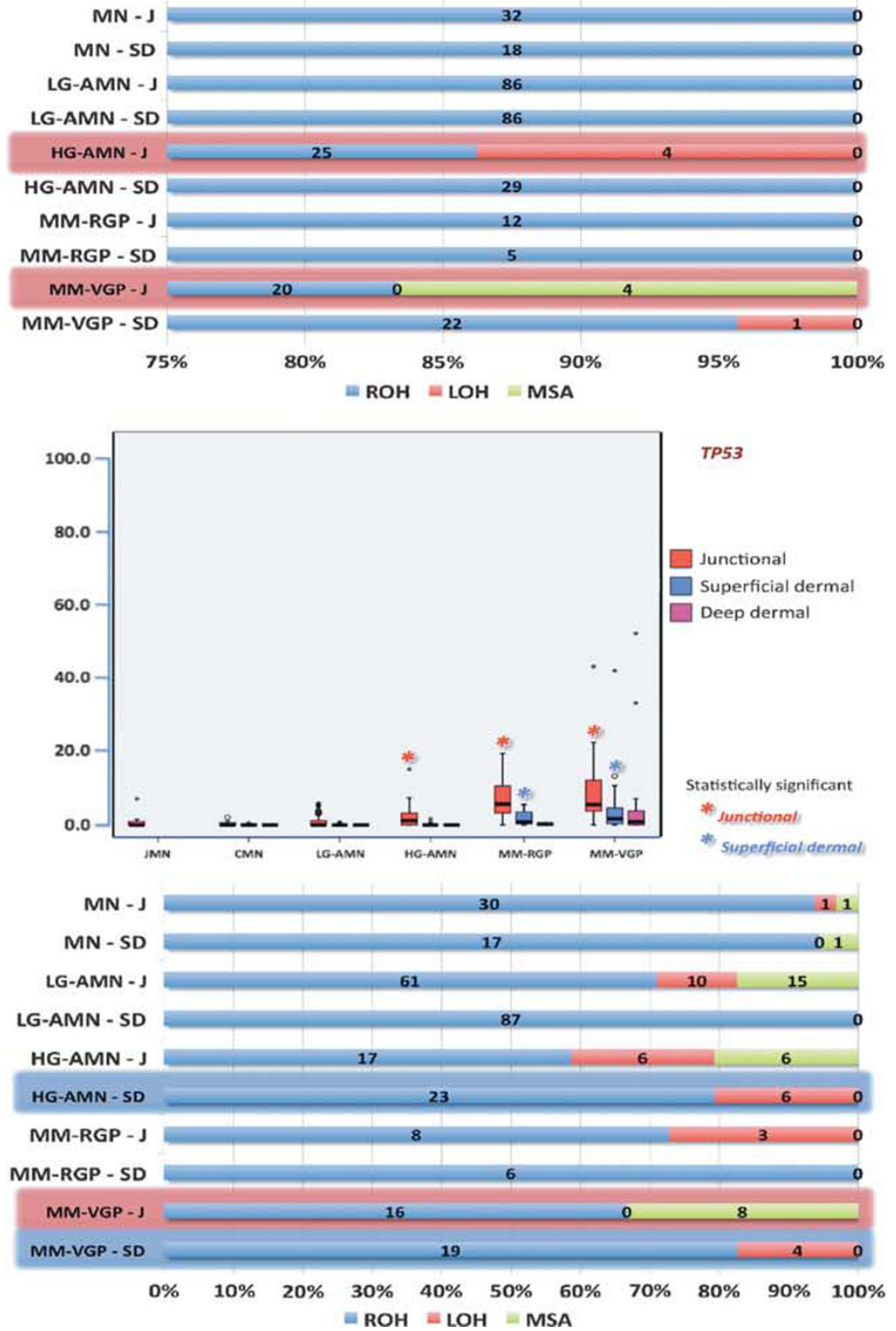

Figure 3 For caption see previous page. 

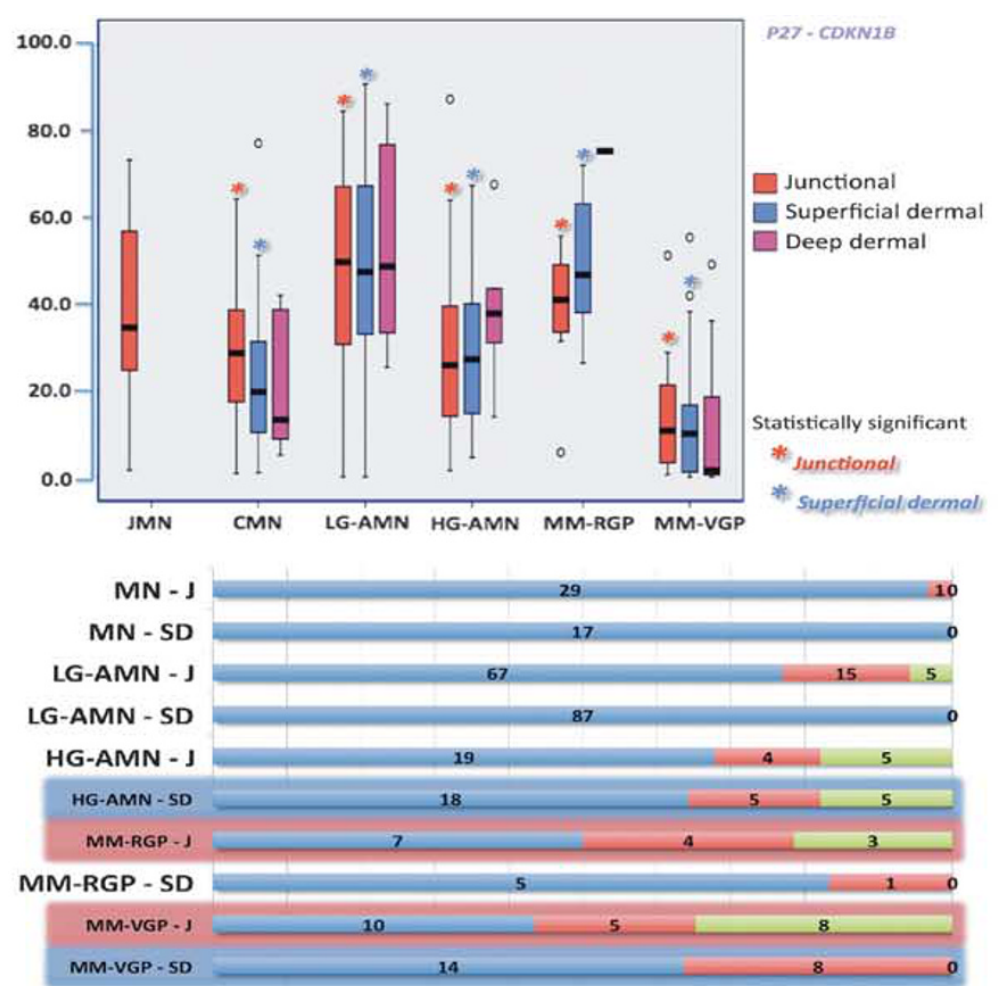

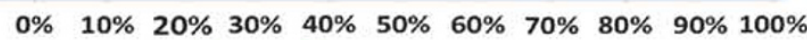
$\equiv$ ROH $=\mathbf{L O H}=$ MSA
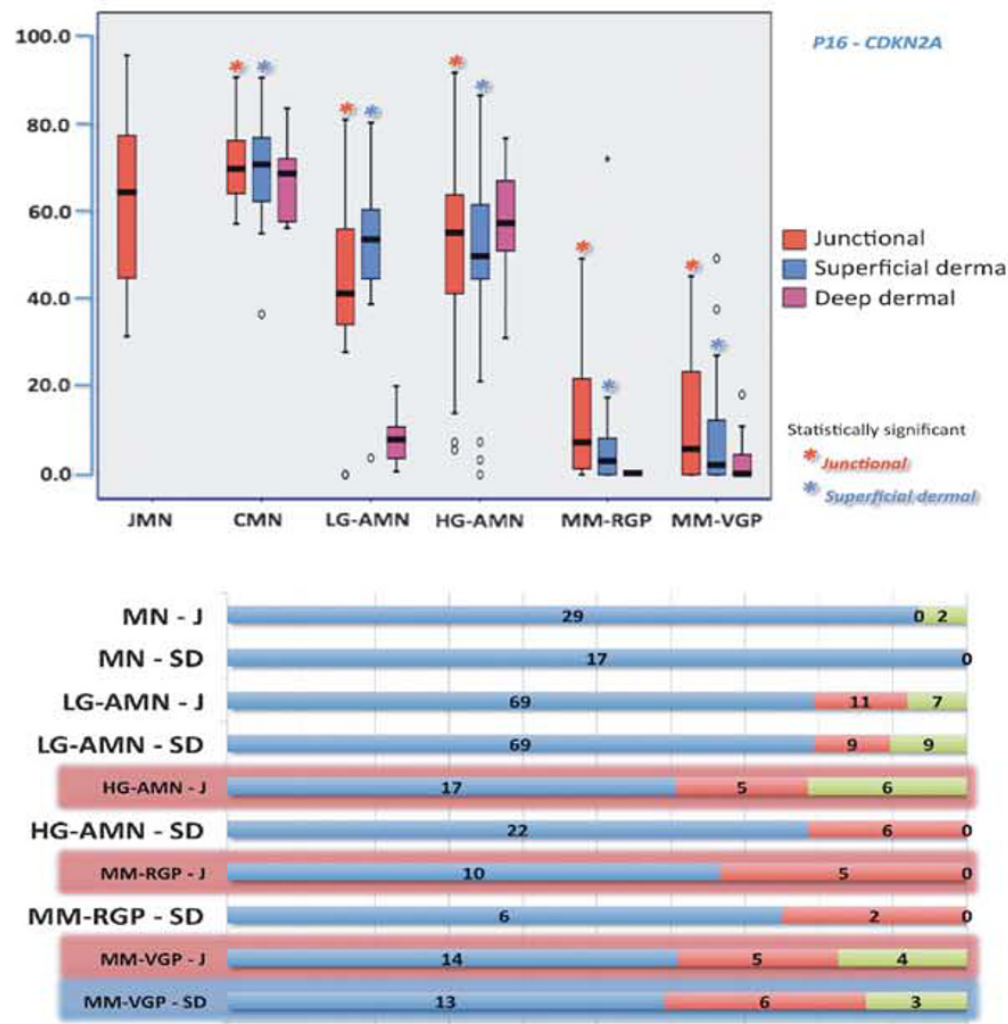

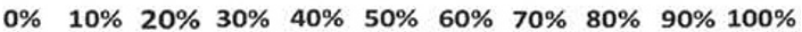

$$
\equiv \text { ROH } \equiv \text { LOH } \equiv \text { MSA }
$$

Figure 3 Continued. 

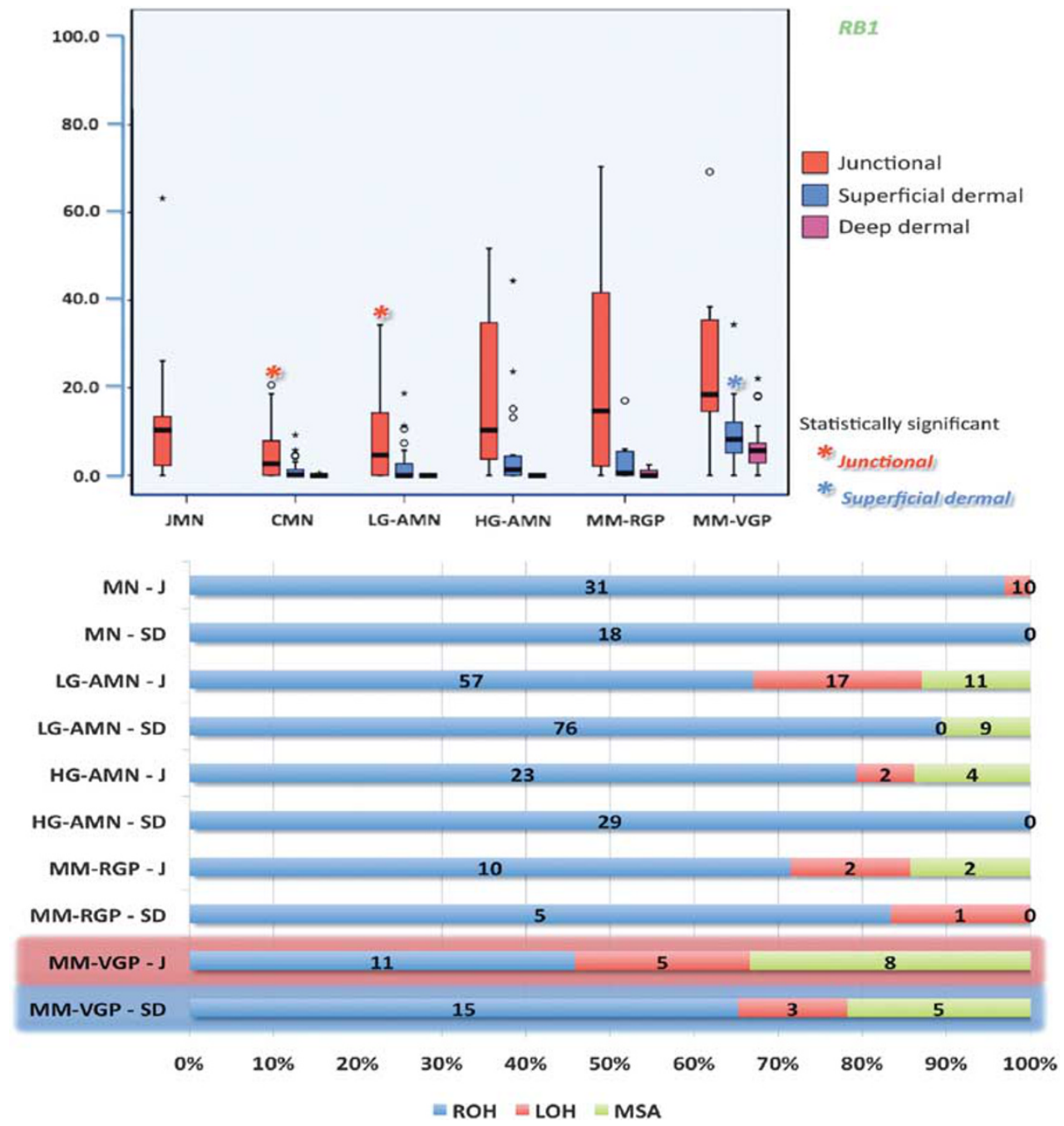

Figure 3 Continued.

tumor cells would support a linear model. However, differential junctional profiles within individual lesions and the distinction between junctional and dermal components support an independent genetic evolution for high-grade atypical melanocytic nevi, and radial- and vertical-growth-phase melanomas. The atypical melanocytic nevus is assumed to represent a malignant melanoma precursor and a marker of increased malignant melanoma risk, ${ }^{36,37}$ the risk correlating with the degree of dysplasia. ${ }^{38,39}$ The atypical melanocytic nevus grading system is controversial and shows low kappa reproducibility, ${ }^{40}$ due to the variable definitions available and the consideration given to moderate dysplasia (either low or high grade).,38-40 These definitions tried to reflect the lesion biology, but there are no studies assessing cell kinetics, cell cycle regulators, and cell survival by grade and tumor cell topography.

High-grade atypical melanocytic nevi predominantly accumulate junctional microsatellite abnormalities of TP53 and the cell cycle regulators CDKN1A and $C D K N 1 B$. High-grade atypical melanocytic nevi revealed the features of established neoplasms (advantageous kinetics, expressed telomerase, and accumulated microsatellite abnormalities, Figure 4), ${ }^{1}$ but different from both radial- and vertical-growthphase malignant melanoma. ${ }^{41,42}$ The microsatellite patterns do not fit a continuous evolution model from high-grade dysplasia to vertical-growth-phase melanoma: The profiles of malignant melanomas in radial and vertical growth phases (phenotype, kinetics, and CCR microsatellite profile) were different, in that radial-growth-phase malignant melanomas showed microsatellite patterns not fitting the transition between high-grade atypical melanocytic nevi and vertical-growth-phase malignant melanomas. This profile unlikely represents a continuous evolution within a common pathway (linear model of progression); this will explain the difficulty in designing common screening or therapeutic targets for these two different malignancies. $^{43}$ It has been normally assumed that tumor progression is a linear process. However, precancerous lesions and early neoplasms (even those with low nuclear grade) can show the genetic and kinetic 
features of established malignancies (clonal proliferation with accumulation of cooperative genetic abnormalities, and advantageous proliferation/ apoptosis disbalance), along with molecular evidence of progression. ${ }^{1,6,17,27,28,44,45}$ This progression would be related to the accumulation of genetic abnormalities and selective segregation of tumor cells with invasive capabilities, which are frequently topographically distributed. ${ }^{20,23,46} \mathrm{~A}$ progressive and significant reduction in marker expression from junctional to deep dermal compartments was a general finding mirrored by the microsatellite profile. These findings proved a significant topographic heterogeneity present in all types of melanocytic lesions, even in early lowgrade superficial ones, and features of intraepithelial malignancy for high-grade atypical melanocytic nevi.

Lesions with more atypical features show more molecular abnormalities than low-grade atypical melanocytic nevi, providing diagnostically useful tools. Dermal TP53 alterations characterized the high-grade dysplasias and the vertical-growth-phase melanomas, while the $C D K N 1 B$ abnormalities defined high-grade dysplastic nevi and melanomas in general. Dermal CDKN2A alterations could be observed in any atypical melanocytic lesion. The cell cycle regulating gene expression and
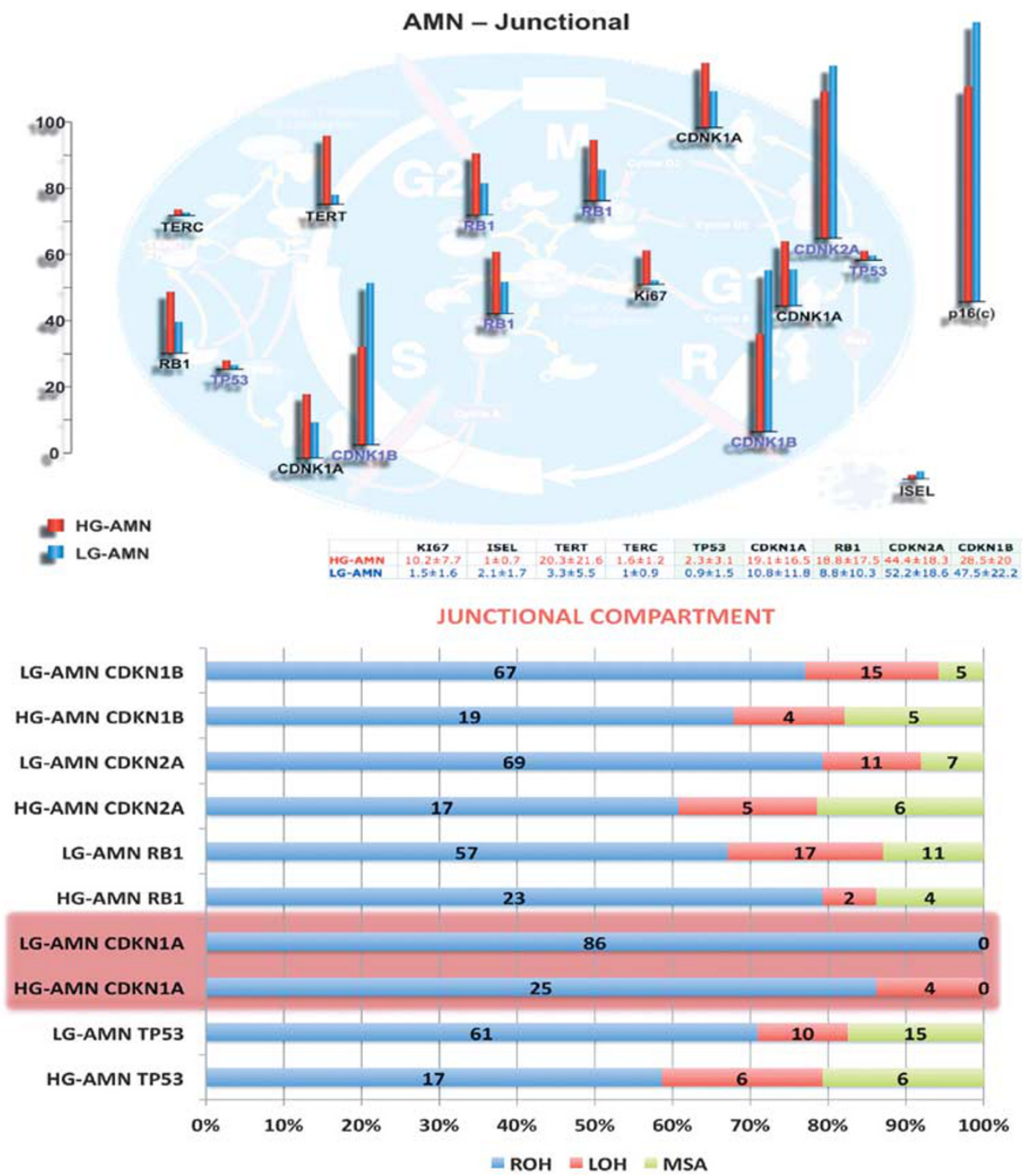

Figure 4 Morphological progression at the junctional compartment of atypical (dysplastic) melanocytic lesions revealed an increase of proliferation and telomerase expression and decrease of apoptosis; the cell cycle regulators showed increasing expression of TP53, $C D K N 1 A$, and $R B 1$, along with decreasing expression of $C D K N 2 A$ and $C D K N 1 B$. These changes revealed statistically significant differences for TP53, RB1, CDKN2A, and CDKN1B at the expression level (no. of positive nuclei/HPF) and for $C D K N 1 A$ at the microsatellite level. Morphological progression at the dermal compartment of atypical (dysplastic) melanocytic lesions revealed an increase of proliferation and telomerase expression and decrease of apoptosis; the cell cycle regulators showed increasing expression of TP53, CDKN2A, and $R B 1$, along with decreasing expression of $C D K N 1 A$ and $C D K N 1 B$. These changes revealed statistically significant differences for $C D K N 1 B$ at the expression level (no. of positive nuclei/HPF) and for TP53, RB1, and CDKN1B at the microsatellite level. 

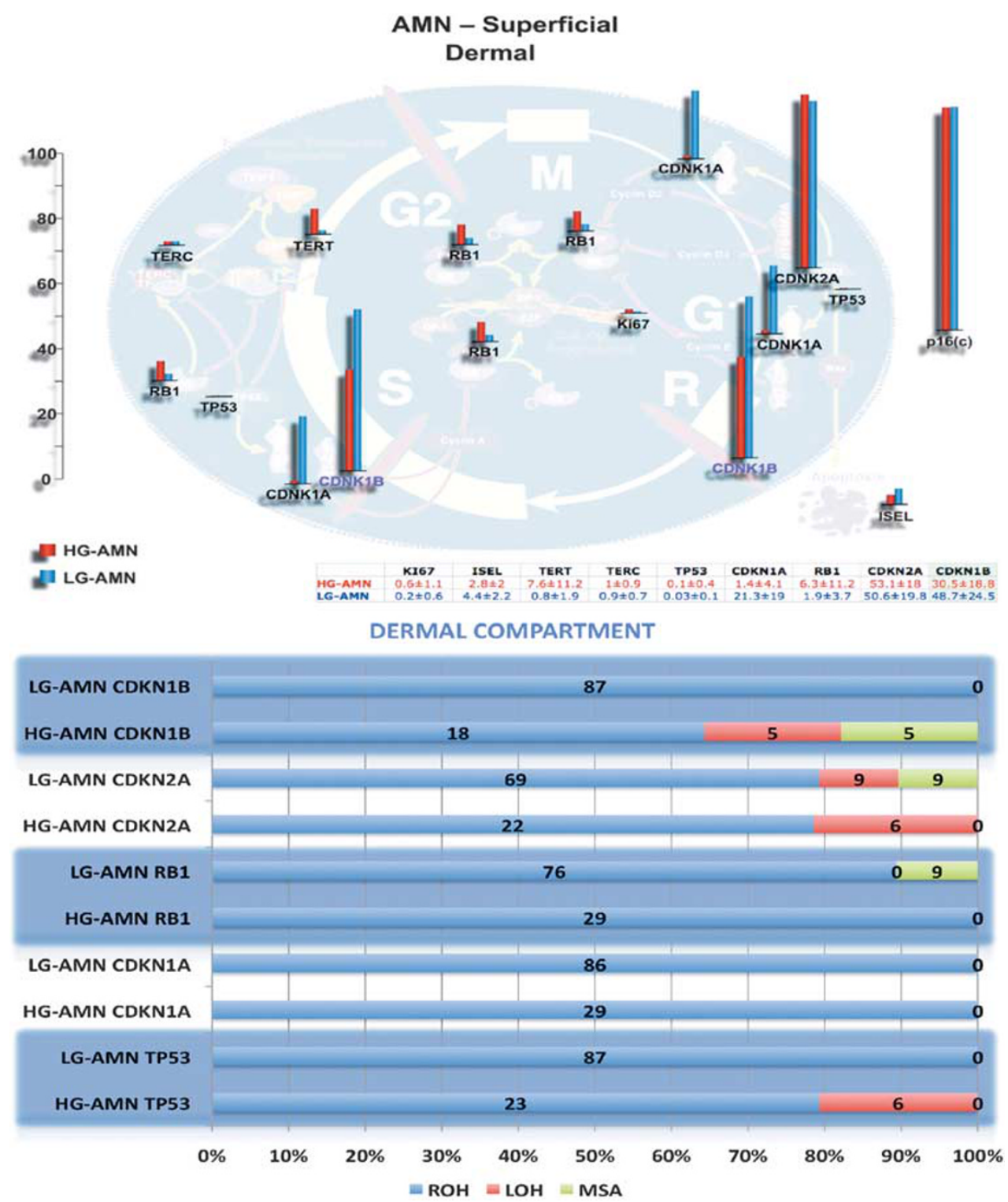

Figure 4 Continued.

microsatellite profiles show a junctional-dermal gradient directly correlating with the histological and topographical grading in atypical melanocytic nevi but not in melanomas. Gene expression abnormalities were more frequent than the corresponding microsatellite alterations, suggesting CCR immunoexpression as a sensitive tool for categorization of atypical melanocytic lesions. The most discriminant marker for most categories was $C D K N 1 B$; although it has a questioned role as malignant melanoma initiator, it is a useful marker in experimental models. ${ }^{4-50}$ These studies highlight CDKN1B's relevance for characterizing malignant melanomas, but not for malignant melanoma precursors, and do not provide information on the microsatellite profile. $C D K N 1 B$ microsatellite abnormalities directly correlated with the degree of atypia in intraepithelial lesions and with progression in malignant melanomas. Although the abnormalities are more frequent in the junctional compartment (initiation), the dermal changes are very useful: they reflect tumor progression biologically and the low background level of abnormalities makes the detection more specific technically. Dermal TP53 alterations characterized high-grade atypical melanocytic nevi and vertical-growth-phase malignant melanomas, while CDKN1B abnormalities defined high-grade atypical melanocytic nevi and malignant melanomas; dermal CDKN2A alterations can be observed in any atypical melanocytic lesion, coexisting with other changes in case of invasive malignancy. These changes are meaningful when considering the kinetics of these lesions: the regressive features of low-grade atypical 
melanocytic nevi make any progression unlikely (as confirmed by the low incidence of microsatellite abnormalities). Only the superficial dermal expression of $C D K N 1 A$ differentiated atypical melanocytic nevi-mild from atypical melanocytic nevi-moderate, suggesting that both lesions cannot be reliably distinguished and would favor to group them as low-grade atypical melanocytic nevi. ${ }^{5,38}$ Low-grade atypical melanocytic nevus has a revealed association with histologic regression, suggesting that inflammation regression is unlikely to be secondary to neoplastic progression. ${ }^{45}$ The histological regression observed in low-grade atypical melanocytic nevi certainly contributes to the atypical clinical picture and is confirmed by a kinetic profile that suggests a regressive lesion; the potential of neoplastic progression in these atypical melanocytic nevi cannot be predicted on histological grounds only. These findings also have diagnostic implications: pleomorphism, hyperchromatism, and at least another nuclear and architectural abnormality is required for a reliable diagnosis of high-grade atypical melanocytic nevi with regression. ${ }^{45}$

In conclusion, early topographic kinetic and microsatellite heterogeneity characterizes atypical melanocytic nevi and suggests an independent evolution for high-grade lesions, which is different from that for invasive malignant melanomas. Progression is better predicted at the dermal compartment and is more likely to follow a divergent rather than a linear model. Conventional melanocytic nevi and low-grade atypical melanocytic nevi show a low incidence of cell cycle regulator abnormalities and kinetic features, which makes progression unlikely.

\section{Acknowledgements}

The protocol used in this study was approved by the Hospital Research Board and Ethical Committees and complied with their requirements.

\section{Disclosure/conflict of interest}

The authors declare no conflict of interest.

\section{Brief statement on paper impact}

This paper addresses intralesional heterogeneity in precancerous melanocytic lesions based on a topographical analysis and highlights the differential selective process in those topographic areas. It also incorporates a dual approach of kinetic (proliferation/apoptosis) and genetic (microsatellite profiles) features to investigate cell segregation in these topographic compartments, using a range of techniques. Finally, the comparative evaluation with benign and malignant (low and high grade) melanomas allows the evaluation of progression in these controversial lesions. This analysis combination makes the paper unique.

\section{References}

1 Diaz-Cano SJ. General morphological and biological features of neoplasms: integration of molecular findings. Histopathology 2008;53:1-19.

2 Clark Jr WH, Elder DE, Guerry Dt, et al. A study of tumor progression: the precursor lesions of superficial spreading and nodular melanoma. Hum Pathol 1984;15:1147-1165.

3 Elder D. Tumor progression, early diagnosis and prognosis of melanoma. Acta Oncol 1999;38:535-547.

4 Elder DE, Clark Jr WH, Elenitsas R, et al. The early and intermediate precursor lesions of tumor progression in the melanocytic system: common acquired nevi and atypical (dysplastic) nevi. Semin Diagn Pathol 1993; 10:18-35.

5 Pozo L, Naase M, Cerio R, et al. Critical analysis of histologic criteria for grading atypical (dysplastic) melanocytic nevi. Am J Clin Pathol 2001;115: 194-204.

6 Pozo-Garcia L, Diaz-Cano SJ. Clonal origin and expansions in neoplasms: biologic and technical aspects must be considered together. Am J Pathol 2003;162: 353-354.

7 Diaz-Cano SJ, Blanes A, Wolfe HJ. PCR techniques for clonality assays. Diagn Mol Pathol 2001;10:24-33.

8 Salomon RN, Diaz-Cano S. Introduction to apoptosis. Diagn Mol Pathol 1995;4:235-238.

9 Nowell PC. The clonal evolution of tumor cell populations. Science 1976;194:23-28.

10 Kerr JF, Winterford CM, Harmon BV. Apoptosis. Its significance in cancer and cancer therapy. Cancer 1994;73:2013-2026.

11 Kerr JF, Wyllie AH, Currie AR. Apoptosis: a basic biological phenomenon with wide-ranging implications in tissue kinetics. Br J Cancer 1972;26:239-257.

12 Schulte-Hermann R, Grasl-Kraupp B, Bursch W. Tumor development and apoptosis. Int Arch Allergy Immunol 1994;105:363-367.

13 Cordon-Cardo C. Mutations of cell cycle regulators. Biological and clinical implications for human neoplasia. Am J Pathol 1995;147:545-560.

14 Haas-Kogan DA, Kogan SC, Levi D, et al. Inhibition of apoptosis by the retinoblastoma gene product. EMBO J 1995;14:461-472.

15 Knudson Jr AG. Hereditary cancers: from discovery to intervention. J Natl Cancer Inst Monogr 1995;17:5-7.

16 Knudson Jr AG. Mutation and cancer: a personal odyssey. Adv Cancer Res 1995;67:1-23.

17 Diaz-Cano SJ, de Miguel M, Blanes A, et al. Germline RET 634 mutation positive MEN 2A-related C-cell hyperplasias have genetic features consistent with intraepithelial neoplasia. J Clin Endocrinol Metab 2001;86:3948-3957.

18 Diaz-Cano SJ. Designing a molecular analysis of clonality in tumours. J Pathol 2000;191:343-344.

19 Blanes A, Diaz-Cano SJ. Complementary analysis of microsatellite tumor profile and mismatch repair defects in colorectal carcinomas. World J Gastroenterol 2006;12:5932-5940.

20 Blanes A, Sanchez-Carrillo JJ, Diaz-Cano SJ. Topographic molecular profile of pheochromocytomas: role 
of somatic down-regulation of mismatch repair. J Clin Endocrinol Metab 2006;91:1150-1158.

21 Baithun SI, Naase M, Blanes A, et al. Molecular and kinetic features of transitional cell carcinomas of the bladder: biological and clinical implications. Virchows Arch 2001;438:289-297.

22 Blanes A, Diaz-Cano SJ. DNA and kinetic heterogeneity during the clonal evolution of adrenocortical proliferative lesions. Hum Pathol 2006;37:1295-1303.

23 Diaz-Cano SJ, Blanes A, Rubio J, et al. Molecular evolution and intratumor heterogeneity by topographic compartments in muscle-invasive transitional cell carcinoma of the urinary bladder. Lab Invest 2000; 80:279-289.

24 Blanes A, Rubio J, Martinez A, et al. Kinetic profiles by topographic compartments in muscle-invasive transitional cell carcinomas of the bladder: role of TP53 and NF1 genes. Am J Clin Pathol 2002;118:93-100.

25 Diaz-Cano SJ. Are PCR artifacts in microdissected samples preventable? Hum Pathol 2001;32:1415-1416.

26 Diaz-Cano SJ, Brady SP. DNA extraction from formalinfixed, paraffin-embedded tissues: protein digestion as a limiting step for retrieval of high-quality DNA. Diagn Mol Pathol 1997;6:342-346.

27 Diaz-Cano SJ, de Miguel M, Blanes A, et al. Clonal patterns in phaeochromocytomas and MEN-2A adrenal medullary hyperplasias: histological and kinetic correlates. J Pathol 2000;192:221-228.

28 Diaz-Cano SJ, de Miguel M, Blanes A, et al. Clonality as expression of distinctive cell kinetics patterns in nodular hyperplasias and adenomas of the adrenal cortex. Am J Pathol 2000;156:311-319.

29 Rubio J, Blanes A, Sanchez-Carrillo JJ, et al. Microsatellite abnormalities and somatic down-regulation of mismatch repair characterize nodular-trabecular muscle-invasive urothelial carcinoma of the bladder. Histopathology 2007;51:458-467.

30 Diaz-Cano SJ. Kinetic topographical heterogeneity in follicular thyroid neoplasms and growth patterns. Histopathology 2007;51:416-418.

31 Diaz-Cano SJ, Garcia-Moliner M, Carney W, et al. Bcl-2 expression and DNA fragmentation in breast carcinoma, pathologic and steroid hormone receptors correlates. Diagn Mol Pathol 1997;6:199-208.

32 Koch M, de Miguel M, Hofler H, et al. Kinetic profiles of intraepithelial and invasive prostatic neoplasias: the key role of down-regulated apoptosis in tumor progression. Virchows Arch 2000;436:413-420.

33 Harjacek M, Diaz-Cano S, De Miguel $\mathrm{M}$, et al. Expression of galectins-1 and -3 correlates with defective mononuclear cell apoptosis in patients with juvenile idiopathic arthritis. J Rheumatol 2001;28: 1914-1922.

34 Clemente C, Cochran AJ, Elder DE, et al. Histopathologic diagnosis of dysplastic nevi: concordance among pathologists convened by the World Health Organization Melanoma Programme. Hum Pathol 1991;22: 313-319.
35 Barnhill RL, Roush GC, Duray PH. Correlation of histologic architectural and cytoplasmic features with nuclear atypia in atypical (dysplastic) nevomelanocytic nevi. Hum Pathol 1990;21:51-58.

36 Takata M, Saida T. Early cancers of the skin: clinical, histopathological, and molecular characteristics. Int J Clin Oncol 2005;10:391-397.

37 Wang Y, Rao U, Mascari R, et al. Molecular analysis of melanoma precursor lesions. Cell Growth Differ 1996; 7:1733-1740.

38 Arumi-Uria M, McNutt NS, Finnerty B. Grading of atypia in nevi: correlation with melanoma risk. Mod Pathol 2003;16:764-771.

39 Shors AR, Kim S, White E, et al. Dysplastic naevi with moderate to severe histological dysplasia: a risk factor for melanoma. Br J Dermatol 2006;155:988-993.

40 Duncan LM, Berwick M, Bruijn JA, et al. Histopathologic recognition and grading of dysplastic melanocytic nevi: an interobserver agreement study. J Invest Dermatol 1993;100:318S-321S.

41 Gimotty PA, Guerry D, Ming ME, et al. Thin primary cutaneous malignant melanoma: a prognostic tree for 10-year metastasis is more accurate than American Joint Committee on Cancer staging. J Clin Oncol 2004; 22:3668-3676.

42 Gimotty PA, Van Belle P, Elder DE, et al. Biologic and prognostic significance of dermal Ki67 expression, mitoses, and tumorigenicity in thin invasive cutaneous melanoma. J Clin Oncol 2005;23:8048-8056.

43 Pozo L, Diaz-Cano SJ. Tumor screening and biology in malignant melanomas. Arch Dermatol 2000;136: 934-935.

44 Diaz-Cano SJ. Molecular mechanisms in melanoma. N Engl J Med 2006;355:1395.

45 Pozo L, Husein E, Blanes A, et al. The correlation of regression with the grade of dysplasia (atypia) in melanocytic naevi. Histopathology 2008;52:387-389.

46 Arif S, Patel J, Blanes A, et al. Cytoarchitectural and kinetic features in the histological evaluation of follicular thyroid neoplasms. Histopathology 2007;50: 750-763.

47 Alonso SR, Ortiz P, Pollan M, et al. Progression in cutaneous malignant melanoma is associated with distinct expression profiles: a tissue microarray-based study. Am J Pathol 2004;164:193-203.

48 Bhatt KV, Hu R, Spofford LS, et al. Mutant B-RAF signaling and cyclin D1 regulate Cks1/S-phase kinaseassociated protein 2-mediated degradation of p27Kip1 in human melanoma cells. Oncogene 2007;26: 1056-1066.

49 Denicourt C, Saenz CC, Datnow B, et al. Relocalized p27Kip1 tumor suppressor functions as a cytoplasmic metastatic oncogene in melanoma. Cancer Res 2007;67: 9238-9243.

50 Zhang H, Schneider J, Rosdahl I. Expression of p16, p27, p53, p73 and Nup88 proteins in matched primary and metastatic melanoma cells. Int J Oncol 2002;21: 43-48. 